\title{
As relações sociais e simbólicas do sistema de viagem, turismo e lazer das periferias do Recife (PE)
}

\author{
Social relations and symbolic system of travel, tourism and leisure \\ on the outskirts of Recife (PE, Brazil)
}

\section{Rosana Eduardo da Silva Leal}

\begin{abstract}
RESUMO
O presente artigo tem por finalidade analisar as relações sociais e simbólicas do sistema de viagem, turismo e lazer existente nas periferias do Recife. Para tanto, considerará as especificidades que embasam os processos de produção, comercialização e consumo de deslocamentos, enfatizando a importância dos organizadores dos trajetos (provedores) e dos bairros para a manutenção de tais práticas. O estudo foi desenvolvido através da pesquisa bibliográfica, seguindo uma perspectiva socioantropológica, bem como pesquisa de campo, com o uso do método etnográfico e registro dos relatos dos provedores. Diante da pesquisa, foi observado que a singularidade deste sistema se dá pela contínua adequação às necessidades, gostos e estilos de vida dos usuários, gerando formas diferenciadas de promover, comercializar e realizar deslocamentos. Tal realidade se concretiza pelas mãos dos provedores, que atuam como mediadores entre os viajantes, os serviços utilizados e as localidades visitadas. As especificidades deste sistema podem ser percebidas desde as modalidades de viagens, passando pelas formas de pagamento, meios de deslocamento, bem como os modos de visitação e hospedagem em destinos turísticos e não turísticos.
\end{abstract}

PALAVRAS-CHAVE: Viagens; Provedores; Bairros Populares; Recife.

\section{ABSTRACT}

This article aims to analyze social relations and symbolic system of travel, tourism and leisure existing on the outskirts of Recife. For that, consider the specific processes that underlie the production, marketing and consumption shifts, emphasizing the importance of the organizers of paths (ISPs) and neighborhoods for maintaining such practices. The study was developed through literature review, following a social anthropological perspective, as well as field research, using the ethnographic method and record the reports of providers. Given the research, it was observed that the uniqueness of this system is given by continuous adaptation to the needs, tastes and lifestyles of users, generating different ways to promote, market and perform displacements. This reality is realized by the hands of providers, who act as mediators between travelers, the services used and the locations visited. The specifics of this system can be perceived from the travel arrangements, through the forms of payment shift means and modes of visitation and accommodation in tourist and not tourist destinations.

KEYWORDS: Travel; Providers; Outskirts; Recife. 


\section{Introdução}

A concepção clássica do viajante difundida nos séculos XVII e XVIII esteve intrinsecamente vinculada a uma experiência europeia, masculina, branca e burguesa, que denotava o sentido de aventura, cientificismo, heroísmo, educação e enobrecimento. Essa compreensão, mesmo nos dias atuais, traz em seu cerne uma ideologia elitista que enquadra nesta categoria algumas classes sociais e deixa de fora outras. Para os não brancos, os não ocidentais e os situados em camadas sociais mais pobres, as viagens têm sido consideradas como não voluntárias, desprovidas de aventura, heroísmo e conhecimento, muitas vezes sob intenso controle dos Estados Nacionais.

Entretanto, ao distanciarmos dessa concepção clássica, podemos perceber uma série de táticas e práticas cotidianas que agregam atores sociais, interesses e graus de liberdade, como acontece com o sistema de viagem, turismo e lazer presente nas periferias do Recife. Esse universo empírico envolve um conjunto de deslocamentos comercializados e consumidos por moradores dos bairros populares da cidade, sendo responsável por levar indivíduos e grupos para destinos turísticos e não turísticos. Trata-se de uma dinâmica socioeconômica que sobrevive sem a tutela do estado e/ou do mercado convencional, estando pautado em valores, regras e modos de pertencimento. A relevância desse sistema está em promover um processo de democratização silenciosa das viagens, do turismo e do lazer, possibilitando o deslocamento de diversos grupos durante todo o ano.

Para analisar tal contexto, o presente artigo tem por finalidade tratar das relações sociais e simbólicas presentes neste sistema. A finalidade do estudo é abordar as especificidades que embasam os processos de produção, comercialização e consumo, considerando ainda a importância dos organizadores dos trajetos (provedores) e dos bairros na manutenção de tais práticas.

A temática será analisada por meio de uma perspectiva socioantropológica, envolvendo discussão teórica e apresentação de dados empíricos. Como recursos metodológicos foram utilizados a pesquisa bibliográfica, bem como pesquisa de campo, com o uso do método etnográfico, que foi responsável por trazer à tona os relatos dos provedores e seus respectivos modos de empreender viagens. Tal conteúdo apresentado é parte do estudo que foi desenvolvido durante o doutoramento no Programa de Pós-Graduação de Antropologia da Universidade Federal de Pernambuco, que foi apresentado durante o XII Encontro Nacional de Turismo de Base Comunitária, que ocorreu em novembro de 2012 em São Paulo.

No artigo buscaremos primeiramente analisar teoricamente a relação entre viagem, turismo e lazer na sociedade moderna, por meio do aporte conceitual de autores das ciências sociais que se debruçaram sobre os respectivos temas. Depois faremos uma reflexão sobre a relação dos bairros com a dinâmica do sistema pesquisado. E posteriormente apresentaremos como ocorre o trabalho dos organizadores dos trajetos (provedores), considerando as especificidades deste ofício. No referido artigo, optou-se pela utilização de nomes fictícios para garantir o anonimato dos envolvidos.

\section{Viagem, turismo e lazer}

"As viagens sempre estiveram presentes na vida das sociedades e em quase todas as agrupações humanas" (QUINTANA, 2006, p.03). Esses deslocamentos foram motivados por fatores que incluíam saúde, desporto, educação, comércio, religião, diversão, entre outros aspectos, estando vinculado a fatores como: necessidade de trabalho, interação social, descoberta, curiosidade, prestígio, conhecimento, aventura ou fruição (ANDRADE, 1993, p.51). 
Entretanto, quando considerarmos a relação entre ócio, trabalho e viagem podemos perceber que os privilégios e restrições entre os grupos sociais estavam presentes ainda nas sociedades pré-capitalistas ocidentais e não ocidentais, como resultado do contexto estrutural que alicerçou os deslocamentos humanos em cada período correspondente. No caso das sociedades ocidentais, as viagens como meio de conhecimento e/ou prazer estiveram em grande medida vinculadas a um habitus ${ }^{1}$ das classes dominantes, acessíveis a uma reduzida camada da população. Porém, a partir do século XX, as viagens de recreio deixam de ser privilégio das elites e se estendem às classes trabalhadoras, sobretudo na Europa e América do Norte, como reflexo da sociedade moderna urbano-industrial. Neste período, a viagem turística tornou-se o "[...] maior fenômeno de deslocamento voluntário da história da humanidade", compreendido como forma de lazer universalmente aspirada pelos que participam da sociedade de consumo (BANDUCCI JR; BARRETTO, 2006, p.08) e transformada em fenômeno massivo e "[...] negócio capitalista de envergadura colossal" (CORDERO ULATE, 2006, p.65).

Desde então o turismo, prática social encontrada em grande parte das sociedades e culturas, tem estado cada vez mais presente na agenda de indivíduos das diversas classes sociais, adquirindo características e significados distintos. Isso porque, o deslocamento turístico faz parte da compulsão pela mobilidade experimentada pela sociedade moderna, iniciada ainda no século XIX e ampliada substancialmente no século XX e XXI. Por isso, apresenta-se "[...] como uma forma de movimento humano dentro de um espectro muito mais amplo de mobilidades sociais e físicas" (COLES; DUVAL; HALL, 2005, p.85), promovendo um fluxo massivo de pessoas, imagens, informações, tecnologias, objetos, culturas e recursos financeiros. Sendo assim, inclui-se num quadro de culturas móveis que abarcam migrações, diásporas e movimentos de segunda residência.

Entretanto, conforme salienta Andrade (1993, p.02-03), mesmo o turismo apresentando -se como modelo dominante de viagem na contemporaneidade, não engloba nem inspira todas as demais formas de deslocamento. $O$ autor deixa claro que a viagem é antes de tudo um paradigma atual que espelha a vida social, e que tem em seu interior o trajeto turístico como um modo particular de deslocar-se por prazer. Para ele, é possível identificarmos uma pluralidade de formas e modos de viajar, que absorvem conflitos e desequilíbrios de liberdade e poder que são determinantes para tais movimentos sócio-espaciais.

Para Krippendorf (2001, p. 36) "o lazer e, sobretudo, as viagens pintam manchas coloridas na tela cinzenta da nossa existência. Elas devem reconstituir, recriar o homem, curar e sustentar o corpo e a alma, proporcionar uma fonte de forças vitais e trazer um sentido à vida". Essa experiência é vivida durante todo o ano entre fins de semana, feriados e férias, fazendo parte do que o autor chamou de "ciclo de reconstituição do ser humano na sociedade industrial", em que se tem a moradia, o trabalho e o lazer no âmbito do cotidiano e a viagem turística como um elemento do anticotidiano. Ambos estão inseridos numa rede de interações mais ampla, sofrendo influência de aspectos como a estrutura econômica (subsistema econômico); a sociedade e seus sistemas de valores (subsistema sociocultural); a política e os Estados Nacionais (subsistema político) e o meio ambiente e seus recursos (subsistema ecológico).

Nessa perspectiva, o turismo aparece como prática de lazer que promove encontros, experiência e comportamentos, bem como efeitos e consequência nos destinos e comunidades locais.

Tais práticas envolvem o conceito de 'afastamento', de uma ruptura limitada com rotinas e práticas bem estabelecidas da vida de todos os dias, permitindo que nossos sentidos se abram para um conjunto de estímulos que contrastam com o cotidiano e o mundano (URRY, 2001, p.17). 
Mas esse afastamento da rotina é sempre temporário, pois, como pontua Krippendorf, viajamos para voltar. Nesse sentido, trata-se de uma

ruptura da monotonia entediante da vida urbana, tecida pela rotina do trabalho e pela repetitividade de ritmos padronizados. Ruptura de um dia-adia temperado pela mesmice da paisagem física e humana e pelos estímulos amortecidos que a indústria cultural a cada noite tenta em vão reavivar. Ruptura, finalmente, do impacto opressivo de obrigações que se multiplicam, acalentadas pela modulação rebarbativa de solicitações atiradas de todos os lados (MIRANDA, 2001, p.11).

Conforme salienta Coriolano (2006, p.42), "em sua essência, turismo é lazer, mas lazer com viagem. Nem todo lazer é turismo, assim como nem toda viagem é turística". Trata-se de um "[...] um ato praticado por pessoas que realizam uma atividade específica de lazer, fora das suas respectivas cidades, e se utilizam, para atingir seus objetivos, de equipamentos e serviços cuja prestação constitui um negócio" (BARRETTO, 2003, p.21).

\section{O bairro e sua gramática social}

O sistema de viagem, turismo e lazer desempenha importante papel no cotidiano de seus produtores e usuários. Para os primeiros apresenta-se como fonte de trabalho, renda e diversão. E para os últimos serve como veículo de convívio social, diversão, aprendizagem e exercício da religiosidade. Este conjunto de práticas resulta de soluções cotidianas que estão em constante diálogo com os lugares e agentes sociais que o produzem e o utilizam, sendo constituídos por um repertório de valores, regras e procedimentos.

Trata-se de um campo de produção, troca e consumo gerador de produções individuais, familiares e associativas, pelo qual circulam bens, pessoas e recursos. Grande parte das redes sociais que o sustenta é proveniente de contextos como a família, a escola, o bairro, a vizinhança e o ambiente de trabalho. Por isso, mesmo estando embasado em efemeridades temporais e espaciais próprias das experiências de deslocamento, consegue proporcionar laços duradouros com seus integrantes. É o que podemos observar no relato de Laerte Batista (Julho/2008) sobre seu trabalho num bairro recifense e sua relação com os moradores.

Eu cheguei no conjunto Muribeca em 1984, quer dizer, estava recém inaugurado. Até o presente momento eu efetuo tudo ali dentro. Têm meninas que viaja comigo que às vezes eu nem sei quem é, e quando chegam, dizem: tu não me conhece mais não é? [...] Porque às vezes eram solteiras, já casaram, hoje já são mães e as filhas já estão viajando comigo. Gerações e gerações. E realmente, me dou muito bem com elas .

Portanto, está embasado no que Caillé (2002, p.65) define como "[...] o conjunto das pessoas com quem o ato de manter relações de pessoa a pessoa, de amizade ou de camaradagem, permite conservar e esperar confiança e fidelidade". Onde residem, os organizadores são legitimados como promotores de viagens e acionados no decorrer do ano conforme as necessidades individuais e coletivas dos moradores. Isso fica claro nas 
falas de duas organizadoras:

Eu acho que aqui em Paratibe e Arthur Lundgren todo mundo sabe que eu faço viagem. Todo mundo sabe (Dona Ednéia, abril/2008).

Minha casa não tem errada não. Quando chega na rua do Hiper, é só perguntar onde é que mora Rosalva que faz viagem e todo mundo ensina. Eu sou muito conhecida (Dona Rosalva, maio/2008).

É o bairro que funda a gramática social deste sistema. É dele que provém grande número de consumidores que viaja e contribui para a divulgação dos trajetos comercializados. Nesta organização coletiva, seus moradores aprendem a conviver pela força da presença cotidiana.

O bairro aparece assim como o lugar onde se manifesta um 'engajamento' social ou, noutros termos: uma arte de conviver com parceiros (vizinhos, comerciantes) que estão ligados a você pelo fato concreto, mas essencial, da proximidade e da repetição (MAYOL, 1996, p.39).

Este elo de vizinhança retira de seus habitantes o anonimato, estimulando o aprendizado da convivência e o ajustamento individual ao meio social, uma vez que, "[...] a coletividade é um lugar social que induz um comportamento prático mediante o qual todo usuário se ajusta ao processo geral do reconhecimento, concedendo uma parte de si mesmo à jurisdição do outro" (MAYOL, 1996, p. 47).

No bairro o acesso ao vizinho se dá pelo elo da proximidade. Trata-se de uma relação que não envolve nem a intimidade nem o anonimato, mas que possibilita o reconhecimento e a identificação dos seus usuários. Entretanto, para que isso aconteça, é preciso que seus habitantes passem por um processo de aprendizagem dos lugares, das pessoas e dos códigos sociais implícitos para que a convivência coletiva seja possível e que a proximidade se concretize.

O bairro é também uma unidade da cidade atravessado pelo sentido do público e do privado. Nele, tais dimensões não estão situadas opostamente, posto que coexistem, tornando-se uma dependente da outra. Tal diálogo remete a categoria pedaço (MAGNANI, 1984), que representa uma terceira dimensão inscrita entre o bairro e a moradia.

O termo na realidade designa aquele espaço intermediário entre o privado (a casa) e o público, onde se desenvolve uma sociabilidade básica, mas ampla que é fundada nos laços familiares, porém mais densa, significativa e estável que as relações formais e individualizadas impostas pela sociedade (MAGNANI, 1984, p. 138).

Trata-se de uma categoria êmica identificada por Magnani (1984) durante sua pesquisa nos bairros populares de São Paulo, que abarca tanto o âmbito espacial quanto relacional. Considerado enquanto "espaço" o pedaço denomina os territórios reconhecidos como lugares de encontro e trocas de informações, como o bar, a padaria, o telefone público, o templo religioso. Já enquanto rede de relações, o termo indica os vínculos sociais baseados em laços de vizinhança, procedência e parentesco que promovem proximidade, formas de lealdade e sentimento de pertencimento. Tal categoria não depende diretamen- 
te do território, pois pode mover-se de acordo com os interesses do grupo, que também negocia continuamente as fronteiras de quem participa ou não dele, como acontece com os grupos pesquisados.

O pedaço representa esta terceira dimensão que é constituído pelo agrupamento de indivíduos semelhantes, que compartilham estilos de vida, costumes, crenças e hábitos comuns, tendo a capacidade de promover formas de solidariedade, sistema de trocas e redes de sociabilidade, posto que,

\begin{abstract}
essa malha de relações assegura aquele mínimo vital e cultural que assegura a sobrevivência, e é no espaço regido por tais relações onde se desenvolve a vida associativa, desfruta-se o lazer, trocam-se informações, pratica-se a devoção - onde se tece, enfim, a trama do cotidiano (MAGNANI, 1984, p. 140).
\end{abstract}

De acordo com Magnani (1884, p.140), o pedaço atua como "uma referência concreta, visível e estável" capaz de conferir identidade ao indivíduo. Por isso, sobretudo para os moradores das periferias dos grandes centros urbanos, que sofrem cotidianamente com a falta de serviços básicos, empregos e equipamentos de lazer, pertencer ao pedaço possibilita acolhimento e reconhecimento social.

No caso do sistema de viagem, turismo e lazer, mesmo havendo uma constante inserção de novos integrantes é o pedaço que constrói a base de sustentação e manutenção desta rede. É ele que garante a permanência e inserção de viajantes, a lealdade aos organizadores e a manutenção das regras implícitas.

Para tanto, absorve muitos dos códigos sociais compartilhados por seus habitantes, tornando-se um reflexo do bairro e de suas redes de relações, já que,

\begin{abstract}
a prática do bairro é uma convenção coletiva tácita, não inscrita, mas legível por todos os usuários através dos códigos da linguagem e do comportamento. Toda submissão a esses códigos, bem como toda transgressão, constitui imediatamente objeto de comentários: existe uma norma, e ela é mesmo bastante pesada para realizar o jogo da exclusão social em face dos 'excêntricos', as pessoas que 'não são/fazem como todos nós' (MAYOL, 1996, p.47).
\end{abstract}

Para participar dos trajetos, é necessário estar em conformidade com o contrato tácito postulado pelos organizadores. Assim, é preciso ter aderência ao sistema de valores, comportamentos, códigos de linguagem e posturas corporais considerados adequados para viajar em grupo. E o que Mayol (1996, p. 49) conceitua de conveniência, considerado como "[...] o gerenciamento simbólico da face pública de cada um de nós desde que nos achamos na rua".

A conveniência promove o reconhecimento e a identificação dos indivíduos perante seus pares, promovendo benefícios simbólicos no âmbito coletivo. Para tanto, proíbe, reprime e inibe comportamentos destoantes, a partir da organização de um repertório de regras e juízos de valor que possibilitam a heterogeneidade social, garantindo a qualidade das relações sociais. Trata-se de um mecanismo de regulação interna, simbólica e não quantificada, que se traduz como um rito dos bairros, fazendo-se presente também entre 
os grupos que viajam.

A conveniência é grosso modo comparável ao sistema de 'caixinha' (ou 'vaquinha'): representa, no nível dos comportamentos, um compromisso pelo qual cada pessoa, renunciando à anarquia das pulsões individuais, contribui com sua cota para a vida coletiva, com o fito de retirar daí benefícios simbólicos necessariamente protelados. Por esse 'preço a pagar' (saber 'comportar-se', ser 'conveniente'), o usuário se torna parceiro de um contrato social que ele se obriga a respeitar para que seja possível a vida cotidiana (MAYOL, 1996, p.39).

O conceito de conveniência foi observado no relato de Irma, uma das organizadoras entrevistadas, quando explicou um incidente com uma passageira que se comportou fora dos padrões aceitos em seu grupo. Conforme Mayol (1996), tal desvio é visto como um atentado contra a integridade social do grupo, reduzindo à qualidade moral do infrator que se torna alvo de punições sociais nem sempre explícitas, como conta a interlocutora:

No carnaval levamos uma pessoa pra viajar: uma juíza. Ela se comportou péssima. E eu faço questão de não convidar ela novamente para meu trabalho, porque ela quis queimar meu filme. Ela bebia e cresceu porque tinha uma certa posição. E achou que tinha o direito de tirar a tranquilidade dos outros, porque estava pagando dentro de uma excursão e achava que podia ser importuna, cantando umas músicas desagradáveis, tirando onda com a cara de todo mundo (Irma, novembro/2008).

Conforme a organizadora, depois deste episódio não "houve mais vaga" no ônibus para a referida viajante, que tentou várias vezes se encaixar nas viagens posteriores sem obter sucesso.

Já Dona Edilma conta que passou por maus bocados com um policial civil que viajava com a família e que depois do ocorrido não mais o recebeu como passageiro de suas viagens:

Ele veio através de uma vizinha de Laura. Um policial que veio com a muIher e o filho. Pense no homem safado. [...] Cheio de safadeza, um vocabulário horrível. [...] Na outra viagem ele ligou e eu disse: não estou fazendo e acabou-se. Ele ligou, a mulher dele ainda ligou. Eu disse: Deus me livre. [...]. A mulher era da mesma qualidade, filho e tudo. Tudo uma raça só. Ele era horrível, horrível. Porque era da polícia e achava que era o máximo. Quando viu uma mulher tomando conta...ele homem, policial, aí ficou cheio de direito. E eu não engrossei com ele porque eu não quis engrossar mesmo. Eu prefiro tirar por menos. Eu digo: há de terminar. Terminou e comigo ele não viaja mais. Ainda mais que ele não mora nem aqui, mora lá pro lado do Janga. Aí quando ligou eu disse: tô fazendo viagem mais não. Pronto e acabou-se (Dona Edilma, outubro/2008).

Esse contrato tácito mantido pelos organizadores promove o compartilhamento de um conjunto de normas e códigos de reconhecimento que contribui para a manutenção das redes sociais implícitas, trazendo benefícios simbólicos aos que agem em conformidade e prejuízos aos que não se submetem. 


\section{Os provedores e o exercício do ofício}

As práticas de viagem, turismo e lazer nas periferias recifenses têm como principais responsáveis os provedores, também conhecidos como fretantes. Tais trabalhadores normalmente são moradores dos bairros populares da cidade, que atuam durante todo o ano no processo de organização, busca de novos participantes, venda e acompanhamento dos deslocamentos. Eles têm como principal função realizar viagens de maneira planejada, segura e agradável direcionadas a espaços naturais, históricos e turísticos, eventos culturais e religiosos, além de centros de compras e diversão (Figura 1). A clientela é formada por grupos de donas de casa, estudantes, trabalhadores, membros de associações de bairro e sindicatos, bem como grupos de igrejas, amigos e/ou parentes.

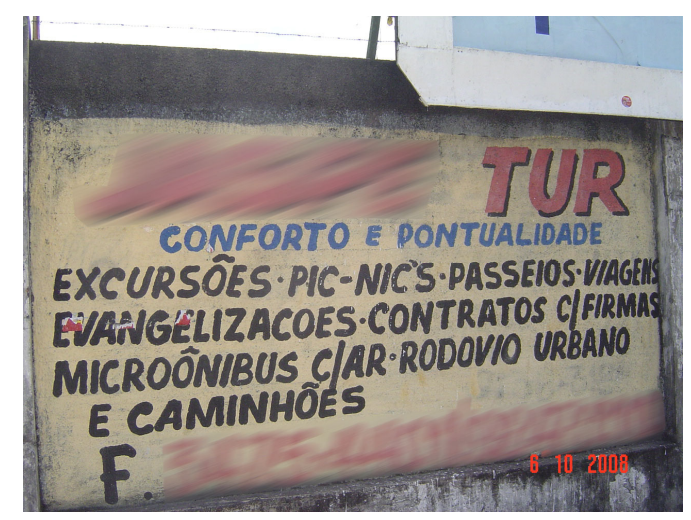

Figura 1: Anúncio em via pública do Recife. Fonte: acervo da autora.

Figure 1: Advertisement on the public roads of Recife. Source: author's collection.

A singularidade desse ofício está na contínua adequação às necessidades, gostos e estilos de vida de seus usuários, gerando formas diferenciadas de promover e realizar viagens, como defende um dos organizadores entrevistados: "[...] o turismo de empresa realmente é um turismo voltado economicamente, financeiramente para favorecer a empresa. No meu caso é para favorecer as pessoas que têm menos oportunidade" (Seu José Carlos, março/2008).

Os respectivos promotores servem como mediadores entre os viajantes e as localidades, sobretudo devido ao conhecimento que possuem sobre lugares, eventos, empresas e serviços, desempenhando importante papel social em seus bairros.

Em todas as etapas das viagens é possível identificar o controle pessoal de quem está à frente da empreitada, pois são eles que decidem as modalidades de viagens, os destinos ofertados, os lugares a serem visitados, os meios de hospedagem utilizados, os preços e formas de pagamento, bem como a orientação e condução dos viajantes antes e durante o trajeto, tendo todo o controle sobre as etapas da viagem. Para isso, costumam contratar tanto serviços de empresas turísticas convencionais (que dão suporte nos serviços de transportes, meios de hospedagens ou guiamento) como também de cooperativas, profissionais autônomos e microempresas locais.

Organizar viagem representa um ofício que pode significar um meio de complementação de renda ou principal fonte financeira. Para muitas mulheres, poder trabalhar com viagens representa uma atividade econômica capaz de garantir a manutenção de suas responsabilidades domésticas, servindo ainda como forma de diversão fora do cotidiano. " $E$ um trabalho misturado com lazer e muita responsabilidade", disse Dona Celeste (setembro/2008).

Como se trata de formas artesanais de produção e comercialização, não há uma pa- 
dronização na condução do negócio. As decisões são tomadas dependendo do perfil do grupo, bem como da biografia e experiência de cada um dos condutores, variando conforme a autoria de quem produz. Por isso, trata-se de uma atividade que permite aos seus produtores utilizarem suas próprias tecnologias e conhecimentos no exercício do ofício.

Ao ser perguntado sobre como costuma guardar as informações dos passageiros, Seu José Carlos (março/2008) explicou: "deveria já estar guardando num computador. Eu não tenho computador. Mas eu guardo numa pasta. [...] Você foi uma primeira vez e se foi uma segunda não precisa mais me dar seus dados pessoais. Eu guardo numa pasta que é o que eu chamo de pasta de viagem".

Grande parte do planejamento das viagens é feito no ambiente doméstico. É no lar que são confeccionadas as programações, sendo o local em que os primeiros contatos começam a ser feitos com os participantes. Além disso, a residência é o lugar onde boa parte das trocas financeiras costuma acontecer, servindo também como ponto de partida e chegada dos ônibus, bem como local de apoio aos viajantes na saída e no retorno da viagem.

Os fretantes contam com a colaboração dos familiares, que, com maior ou menor grau de envolvimento, atuam no processo da organização e concretização dos deslocamentos, dando suporte ao planejamento, divulgação, trocas financeiras, atendimento telefônico, contabilidade e recebimento de parcelas na residência ou no trabalho dos participantes.

Em muitos casos, os filhos começam a participar das viagens desde a infância, tornando-se paulatinamente o braço direito de seus pais, como nos esclarece Seu José Carlos:

A família ajuda. [...] Eles ajudam no seguinte aspecto de, por exemplo, pessoas lá em casa ligam pra mim e diz: têm três pessoas ou quatro querendo ir. Aí eu mando levar o roteiro lá, mando pegar a importância pra pagar ônibus e hotel, ele manda uma parte, aí eu já aproveito e mando o roteiro. Nessa ida que meu filho vai, já pega uma parte, leva o roteiro, a programação e pega os dados da pessoa, tipo assim, identidade, nome completo e tudo, porque tem que fazer seguro na empresa e o ônibus tem que ser assegurado. Aí eles me ajudam neste aspecto. As vezes eu não estou em casa, atendem o telefone. Uma pessoa que está querendo ir, eles passam as informações. E no dia da viagem é festa pra todo mundo. Eles colaboram também no aspecto de ajudar as pessoas. Já que eu tenho, como você vê, a dificuldade física, que eu sou deficiente físico, eu tenho uma certa dificuldade. Eles ajudam na questão de organizar bagagem..., descer, subir, etc. (Março/2008).

No caso de Dona Celeste, o marido e o filho ajudam da seguinte forma:

[Meu marido] ajuda os idosos do ônibus a descerem e pega no braço. Quando a gente tá pra ir embora, ele começa a juntar o povo tudinho, tá entendendo? Dentro do ônibus ele confere se está todo mundo certo. Eu também confiro. Aí quando tá todo mundo certinho aí ele diz: pode ir motor. E vem embora. Meu filho também, quando ele tá folgando ele também trabalha (Setembro/2008).

$\mathrm{Na}$ casa de Laerte Batista, toda a família se envolve nas tarefas cotidianas ligadas ao ofício. "Quando eu estou na rua, minha esposa está em casa anotando os telefonemas. Eu tenho uma menina com nove anos que sai anotando todos os recados. Quando eu chego, ela já tem tudo anotadinho" (Julho/2008).

Os fretantes têm a seu favor algo cada vez mais difícil no mundo moderno dos negó- 
cios: a fidelidade dos participantes. Alguns viajam há mais de 10 anos com o mesmo organizador, explicando que se trata de uma grande família. " $E$ um grande encontro, pois todos se conhecem. É um momento de confraternização. É o Turismo de Amigos", como definiu um viajante em conversa informal.

Cada organizador possui suas próprias estratégias para incluir novos integrantes, não havendo regras fixas quanto a esse procedimento. A inserção dos novatos dependerá em grande parte da maneira como as viagens são divulgadas.

Os fretantes que não promovem as viagens através de cartazes e jornais só recebem novos viajantes sob a indicação de pessoas conhecidas. Esta é uma forma de proteção quanto a problemas financeiros e comportamentais antes e durante os percursos, como relatou Dona Edilma (outubro/2008): "Se você, que eu não the conheço, chegasse aqui pra viajar comigo, era preciso que você me dissesse quem Ihe trouxe, senão, não ia não. Eu não levo não. Se eu não souber quem foi que trouxe, eu não levo não. Eu tenho é medo. Eu morro de medo de assalto, de tudo". Nestes casos, é preciso ter certas qualidades pessoais compatíveis com as exigências dos responsáveis para poder tornar-se parte da rede de clientes, como declarou Irma (novembro/2008):

\begin{abstract}
Depende de teus modos, de tua educação, da tua recepção. Da maneira que você vai conversar comigo. Eu digo: eu vou fechar uma viagem e vou ver se consigo uma vaga. Vou ver se realmente tem uma vaga. Isso se chama seleção. É necessário porque eu não posso botar qualquer pessoa dentro de um ônibus para desfazer de ninguém. [...]. O seu comportamento é que vai me dizer. No dia-a-dia eu procuro saber quem te indicou e como é seu comportamento. A questão é você ir e trazer outras pessoas e não você ir e queimar meu filme e acabar com meu trabalho. É necessário fazer essa seleção porque senão o turismo não é o mesmo.
\end{abstract}

Para os fretantes que optam por divulgar suas viagens em anúncios em jornais ou locais públicos, a incorporação de participantes acontece mediante o contato pessoal prévio, em que se decidirá a possibilidade ou não de integração ao grupo.

\title{
Considerações finais
}

Ainda que haja atualmente uma relativa facilidade promovida pelo mercado, as viagens e o turismo continuam sendo experimentados, sobretudo, por àqueles que têm a possibilidade de suplantar as necessidades cotidianas latentes e que podem liberar-se do trabalho para visitar lugares fora do local de residência. "Como o turismo interno a preços de mercado restringe-se aos que podem pagá-lo, isto é, os que têm renda suficiente para gastar o excedente em consumo de serviços de recreação e turismo, grande parte da população fica fora dessas possibilidades" (BOULLÓN, 2004, p. 88).

Entretanto, a preocupação com a necessidade de sobrevivência não implica dizer que as classes populares estejam à margem do campo das viagens e turismo em seu dia-a-dia, já que mesmo deixando muitas vezes de ser contempladas pelo mercado ou pelo Estado, tais grupos seguem protagonizando práticas entre suas redes sociais ${ }^{2}$ que respondem às necessidades de deslocamento como meio de complementação de renda, forma de lazer, sociabilidade, consumo ou exercício da religiosidade.

Por isso, não é preciso muito esforço para percebermos a não obediência dos mais fracos diante dos padrões hegemônicos da sociedade capitalista, pois, como pontua Nicolas, 
"[...] os atores individuais da base social edificaram também, de maneira espontânea, contrapoderes com o objetivo de consolidarem sua margem de iniciativa" (NICOLAS, 2002, p. 38). Estes geram uma série de produções sem o domínio estatal ou mercantil que crescem e se ramificam no tecido social com suas próprias lógicas, tecnologias e modos de fazer, mobilizando minúsculos procedimentos cotidianos que indicam o poder das ações anônimas em ressignificar o que está posto pelos padrões dominantes.

Por isso, consideramos que o sistema de viagem, turismo e lazer nas periferias do Recife está pautado em outras lógicas socioeconômicas diferenciadas, estando embasado em uma economia de trocas simbólicas de base comunitária, que garante a vitalidade e a manutenção dos empreendimentos. Trata-se de um universo socioeconômico gestado na base da pirâmide, que envolve relações de amizade, confiança e lealdade, cuja dinâmica não reflete um todo coerente, pois absorve maneiras de fazer e modalidades de viagem, resultando, portanto, da "[...] criatividade dispersa, tática e bricoladora dos grupos ou indivíduos" (CERTEAU, 2007, p.41).

Esse universo de trocas, que ultrapassa o sentido de compra e venda mercantil, é resultante da fala e das práticas do homem comum, que transforma o cotidiano em ambiente propício para o desenvolvimento dos seus saberes.

Diante da pesquisa desenvolvida, foi possível observar que enquanto objeto de estudo, a contribuição deste sistema se dá pelas especificidades com que empreendem as viagens, pelas formas de pagamento, modos e meios de deslocamento, bem como as formas de visitação e hospedagem. Tal realidade se concretiza pelas mãos dos provedores, que atuam como mediadores entre os viajantes, os serviços utilizados e as localidades visitadas, tornando-se um importante campo de estudos multidisciplinares. Tal contexto empírico é capaz de contribuir para a relativização dos estudos sobre viagem, turismo e lazer, na medida em que dar a ver indivíduos, práticas e relações sociais ainda pouco estudadas pela academia.

\section{Referências bibliográficas}

ANDRADE, P. de. Sociologia da Viagem: o quotidiano e os seus inter-trajectos. Revista Crítica de Ciências Sociais. Coimbra, n.37, p. 51-77, jun.1993.

BANDUCCI JR, Á.; BARRETTO, M. (Orgs.). Turismo e identidade local: uma visão antropológica. 5. ed. Campinas: Papirus, 2006.

BARRETTO, M. O imprescindível aporte das ciências sociais para o planejamento e a compreensão do turismo. Horizontes Antropológicos, Porto Alegre, v. 09, n.20, p.15-29, out.2003.

BOULLÓN, R. Atividades turísticas e recreativas: o homem como protagonista. Bauru, SP: EDUSC, 2004.

BOURDIEU, P. Esboço de uma Teoria da Prática. In: ORTIZ, R. (Org.). Pierre Bourdieu. São Paulo: Ática, 1983. p. 46-81.

CAILLÉ, A. Antropologia do Dom: o terceiro paradigma. Petrópolis: Vozes, 2002.

CERTEAU, M. A invenção do cotidiano 1: artes de fazer. Petrópolis, RJ: Vozes, 2007.

COLES, T.; DUVAL, D.T.; HALL, C. M. Sobre el turismo y la movilidad en tiempos de movimiento y conjetura posdisciplinar. Política y Sociedad, Madri, v.42, n.1, p.85-99, 2005.

CORDERO ULATE, A. Nuevos ejes de acumulación y naturaleza. El caso del turismo. Buenos Aires: CLACSO, 2006.

CORIOLANO, L. N. M. T. O turismo nos discursos, nas políticas e no combate à pobreza. 
São Paulo: Anablumme, 2006.

KRIPPENDORF, J. Sociologia do Turismo: para uma nova compreensão do lazer e das viagens. São Paulo: Aleph, 2001.

MAGNANI, J. G. Festa no Pedaço: cultura popular e lazer na cidade. São Paulo: Ed.Brasiliense, 1984.

MARTINS, P. H. A sociologia de Marcel Mauss: dádiva, simbolismo e associação. Revista Crítica de Ciências Sociais. Lisboa, n. 73, p. 45-66, dez.2005.

MAYOL, P. Morar. In: CERTEAU, M.; GIARD, L.; MAYOL, P. A invenção do cotidiano 2: morar, cozinhar. Petrópolis: Vozes, 1996, pp.35-185.

MIRANDA, D. S. Apresentação. In: URRY, J. O olhar do turista: lazer e viagens nas sociedades contemporâneas. 3. ed. São Paulo: Studio Nobel/SESC, 2001, p.09-11.

NICOLAS, G. O dom ritual, face velada da modernidade. In: MARTINS, P. H. (Orgs). A dádiva entre os modernos: discussão sobre os fundamentos e as regras do social. Petrópolis: Vozes, 2002. p.33-62.

QUINTANA, V. M. Ocio y turismo en la sociedad atual: los viajes, el tempo libre y el entretenimiento en el mundo globalizado. Madrid: Mc Graw-Hill/Interamericana de España, 2006.

URRY, J. O olhar do turista: lazer e viagens nas sociedades contemporâneas. 3. ed. São Paulo: Studio Nobel/SESC, 2001.

\begin{abstract}
Notas
${ }^{1}$ Para Bourdieu (1983), o habitus é concebido como a dimensão de um aprendizado passado, que cria uma segunda dimensão do homem e tende a conformar e orientar a ação através da interiorização das normas e dos valores, incluindo o sistema de classificações que preexiste às representações sociais. Nesse sentido, as ações individuais são concretamente realizadas, porém as chances de efetiva-las encontram-se objetivamente estruturadas no interior da sociedade. Conforme o autor, o gosto não é uma simples subjetividade, mas algo objetivamente interiorizado.

2 "A rede é o conjunto das pessoas com quem o ato de manter relações de pessoa a pessoa, de amizade ou de camaradagem, permite conservar e esperar confiança e fidelidade" (CAILLÉ, 2002, p.65).
\end{abstract}

Rosana Eduardo da Silva Leal: Universidade Federal de Sergipe, Aracaju, SE, Brasil.

Email: rosanaeduardo@yahoo.com.br

Link para o currículo Lattes: http://lattes.cnpq.br/5977858829825216

Data de submissão: 30 de junho de 2012

Data de recebimento de correções: 20 de novembro de 2012

Data do aceite: 20 de novembro de 2012

Avaliado anonimamente 